Inger Askehave

\title{
Communicative Purpose as Genre Determinant
}

\begin{abstract}
Through the years researchers and LSP teachers alike have used various parameters for classifying texts. This article sets out to discuss the notion of 'communicative purpose' as a means for classifying text. It points to some of the difficulties associated with the functional approaches to genre classification in general and the notion of "communicative purpose" in particular.
\end{abstract}

\section{Introduction}

"The urge to classify is fundamental", Miller says in her 1984 article 'Genre as Social Action'. This fundamental urge is also apparent when dealing with texts. The last thirty years have seen a growing interest in the classification of texts. It began in the 1960s when researchers like M.A.K. Halliday - in an attempt to react against Chomskyan formalism - began to study variations of language and to categorise these variations according to linguistic properties (Halliday et al. 1964) and later according to situational dimensions (Halliday 1978).

Through the years different parameters for classifying texts have been used. Thus researchers have been trying to group texts according to:

1. Linguistics features (e.g. Tarone et al 1981, Henderson \& Hewings 1987, Biber 1988, Salager-Meyer 1994)

2. Situational features (e.g. Halliday 1978, Halliday \& Hasan 1989)

3. Functional features (e.g. Swales 1990, Bhatia 1993, Eggins 1994, Eggins \& Martin 1997, Martin 1985a, Martin 1992), Miller 1984) The aim of this paper is to discuss and evaluate one of the approaches mentioned above - namely the functional approach which tries to clas-

\footnotetext{
* Inger Askehave

Engelsk Institut

Handelshфjskolen i Århus

Fuglesangs Allé 4

DK-8210 Arhus V
} 
sify texts according to their functional features or 'communicative purpose'.

\section{Approaches to Functional Classification}

The functional theories, which will be evaluated here, are those belonging to the Anglo-Saxon tradition of genre analysis. Though working independently of each other, the two researchers, Swales (1990) and Martin (1992), have come up with very similar ideas about classifying text.

Martin's framework for classifying texts (his so-called genre theory) originates from the Hallidayan systemic functional grammar and could be seen as an extension to Halliday's work on language varieties.

Martin regards genre as a:

"[...] staged, goal-oriented, purposeful activity in which speakers engage as members of our culture"

(Martin 1984: 25)

Martin tries to categorise language use in terms of what he calls the culturally appropriate goals speakers are trying to achieve by means of language. In his framework such goals may for instance be to describe, explain, or narrate something realised by the genres 'description', 'explanation' and 'narration'.

I have criticised Martin's use of the term genre elsewhere and shall not go into a detailed discussion of it here (see Askehave in press). Suffice to say that the factor determining genre membership is that of the goal or 'communicative purpose' of a text.

Furthermore, Martin suggests that the major linguistic reflex of 'purpose' in a text is the staging structure by which a text of a particular genre unfolds. Thus when Martin defines 'genre' as a 'staged, goal-oriented, purposeful activity', he is referring to the fact that genres lay down the way to go about accomplishing such purposeful activities. In other words when people try to accomplish an activity type by means of language, social convention has established that they adopt certain strategies which can be regarded as stages through which they move to achieve the purpose of the interaction. The staged and goal-oriented organisation of genre is expressed linguistically through a functional constituent structure referred to as the 'schematic structure': 
"Schematic structure represents the positive contribution genre makes to a text: a way of getting from A to B in the way a given culture accomplishes whatever the genre in question is functioning to do in that culture".

(Martin 185: 25)

However, the primary determinant of genre membership is that of 'purpose' whereas schematic structure and linguistic features are regarded as dimensions to the realisation of genres (Eggins 1994: 36).

Now let's take a look at another functional approach to genre classification developed by Swales (1990).

According to Swales (1990: 58):

"A genre comprises a class of communicative events, the members of which share some set of communicative purposes. These purposes are recognized by the expert members of the parent discourse community and thereby constitute the rationale for the genre. This rationale shapes the schematic structure of the discourse and influences and constrains choice of content and style".

Again we see genres defined not as texts but rather as social or communicative events. Furthermore, the definition tries to set up a realisational relationship between the purpose accomplished by a genre and the structure of the genre and suggests that the communicative purpose of a genre shapes the genre and provides it with an internal structure a schematic structure.

At the same time it is important to note that although the definition acknowledges other characteristics of genres such as content, form, intended audience, medium etc., it classifies texts/language use as belonging to particular genres on the basis of functional criteria i.e. the communicative purpose.

"Communicative purpose is both a privileged criterion and one that operates to keep the scope of a genre as here conceived narrowly focused on comparable rhetorical action. In addition to purpose, exemplars of a genre exhibit various patterns of similarity in terms of structure, style, content and intended audience. If all high probability expectations are realized, the exemplar will be viewed as prototypical by the parent discourse community".

Swales (1990: 58)

Both frameworks have been widely applied by scholars making genre analyses of every day texts as well as LSP texts. In some cases the prac- 
tical application of the genre theories has thrown light on some of the uncertainties or problems which the theories present.

Bhatia (1993), who bases his genre analyses on Swales' framework, claims for example that promotion letters and job applications belong to the same genre because the overall communicative purpose of both texts is to promote something (be it a product, company or person). On the other hand one might argue that Bhatia's 'communicative purpose' is too general as it results in groupings of texts which - only at a very general level - can be said to serve the same purpose. Another point for discussion has been that of the criteria used for identifying the schematic structure of genres i.e. whether a move or stage in a schematic structure can be determined by the content of the move, grammatical or lexical patterns or functional features of the move (Paltridge 1994).

However, as far as I know, no one has questioned the rather slippery notion of 'communicative purpose' which - as we have just seen - is used as the primary determinant of genre-membership in both approaches. The rest of this article will, therefore, address the notion of 'communicative purpose' and point to some of the difficulties associated with the use of the term for classifying texts.

\section{Communicative Purpose}

Even though the notion of 'communicative purpose' plays a fundamental role in the two genre theories a clear definition and thorough discussion of the term is difficult to find in both Martin and Swales' work.

\subsection{Swales and Communicative Purpose}

In his book 'Genre Analysis' Swales (1990) comments on the challenges and difficulties associated with the use of 'communicative purpose' as genre determinant. First of all he comments on the slippery nature of the term:

Placing the primary determinant of genre-membership on shared purpose rather than on similarities of form or some other criterion is to take a position that accords with that of Miller (1984) or Martin (1985a). The decision is based on the assumption that, except for a few interesting and exceptional cases, genres are communicative vehicles for the achievement of goals. At this juncture, it may be objected that purpose is a somewhat less overt and demonstrable feature than, say, 
form and therefore serves less well as a primary criterion. However, the fact that purposes of some genres may be hard to get at is itself of considerable heuristic value. Stressing the primacy of purpose may require the analyst to undertake a fair amount of independent and open-minded investigation, thus offering protection against a facile classification based on stylistic feature and inherited beliefs, such as typifying research articles as simple reports of experiments".

(Swales 1990: 46)

Furthermore, he comments on the difficulties of identifying the communicative purpose of a genre and the need - in some cases - to work with sets of purposes:

"While news broadcasts are doubtless designed to keep their audiences up to date with events in the world (including verbal events), they may also have purposes of moulding public opinion, organizing public behaviour (as in an emergency), or presenting the controllers and paymaster of the broadcasting organization in a favorable light".

(Swales 1990: 47)

However, a clear definition of the phenomenon of 'communicative purpose' is difficult to find. Such a definition would, however, be very relevant as Swales seems to introduce two types of communicative purpose in his definition: what I shall refer to here as the 'official' communicative purpose and the 'hidden' communicative.

For example when he characterises the purpose of news broadcasts as being that of keeping their audiences up to date with events in the world, he seems to talk about what I suggest we call the 'official' purpose of news broadcasts - the generally socially acceptable purpose of news broadcasts. However, at the same time Swales argues that the purpose of a news broadcasts may also be to mould public opinion, organising public behaviour or presenting the controllers and paymaster of the broadcasting organisation in a favourable light. Thus here the purpose of the text could be characterised as the 'hidden' purpose - a more covert purpose - which is not necessarily accepted or known by all users of the genre.

The same distinction applies when Swales accounts for the purpose of research articles where he says that "[..] it remains the case that research articles are rarely simple narratives of investigations. Instead, they are complexly distanced reconstructions of research activities, at least part of this reconstructive process deriving from a need to anti- 
cipate and discountenance negative reactions to the knowledge claims being advanced"' (Swales 1990: 175 - my emphasis).

My point is that Swales never comments on the distinction which I would argue exists between the official and the hidden purposes of a text. And as we shall see later such a distinction is quite important if we use the term 'communicative purpose' as genre determinant.

\subsection{Martin and Communicative Purpose}

Martin's use of the term 'communicative purpose' is problematic in a slightly different way. In Martin (1992) the following characterisation of 'telos' (communicative purpose) can be found:

"It should be stressed here that bringing telos into contextual theory at this point in no way implies that the text is being interpreted as the realisation of speaker's intentions; genres are social processes, and their purpose is being interpreted here in social, not psychological terms". (Martin 1992: 503)

Thus here we see that Martin explicitly declares that he is not interested in what goes on in the mind of the speaker. In other words he is not concerned with the fact that news broadcasts may serve other purposes apart from that of 'keeping their audiences up to date with events in the world'. He regards 'telos' or 'communicative purpose' as a purely 'social phenomenon'.

However, the problem here is that the social phenomena which Martin refers, to are rather limited and general. The reason is that when Martin talks about genres/social processes he tends to equal his concept of 'genre' and the concept of 'text types' (such as 'descriptions', 'explanations', 'instructions', etc.) as used in other European text linguistic traditions such as Werlich (1976).

'It is important to note [...] that the term 'letter' refers to a mode and not a genre".

(Martin 1985b: 17)

And he continues:

"This distinction between the purpose of a text (genre) and the way in which it is transmitted (mode) is an important one because so many of our folk linguistic terms confuse mode and genre. Letters to the editor for example are usually hortatory expositions sent through the mail and have much more in common with sermons and political speeches than with other types of letter".

(Martin 1985b: 17) 
Consequently, his concern with the goal or communicative purpose of texts as social phenomena tends to limit itself to what he calls the "social' purpose of text types (such as to describe, explain, instruct, etc.).

Therefore, when Martin sets out to explain what the purpose of texts is - why we say this or that on a particular occasion - his account usually restricts itself to a small group of about six or seven different rhetorical purposes such as to narrate, to inform, to instruct, etc. These purposes are then realised linguistically in six or seven text types such as the narrative, informative, instructional, etc. text types (for a more extensive criticism of this see Askehave (in press).

The strange thing is, however, that in some cases one can in fact find examples of 'purposes' in Martin's work which tend to equal what I would call 'hidden' purposes. For example Eggins and Martin (1997) comment on a public talk given by Chomsky and refer to this text as having the purpose of 'delivering social commentary' or simply 'stirring'. Such purposes are definitely different from the purposes of text types mentioned above and closer to what Swales to some extent seems to understand by 'communicative purposes'.

\section{Communicative Purpose as Genre Determinant}

The absence of a clear consensus as to what communicative purpose is and - if we finally decide what we understand by 'communicative purpose' - the fact that sets of purposes may be associated with a text makes it very difficult to use the concept as a tool for categorising texts and for analysing texts in general.

Let me illustrate this difficulty. In my Ph.D-thesis (Askehave 1998) I try to establish what the purpose of a company brochure is. Not in order to categorise the text as such but - inspired by the theories of Martin and Swales about communication being a purposeful activity in order to look at the company brochure as a "[...] staged, goal-oriented, purposeful activity in which speakers engage as members of our culture" (Martin 1984: 25). However, before embarking on a thorough analysis, I consulted literature concerned with the purpose of company brochures. In Bhatia's genre analysis (Bhatia 1993: 59), which is based on Swales framework, the company brochure is regarded as a 'promotional genre' and according to Bhatia the communicative purpose is that of 'promoting something' (in this case the company). However, the 
problem with this definition is that it is so general that it does not contribute much to the description of the genre as an intentional and purposeful activity from the view of the sender.

In my thesis, however, I was interested in taking a closer look at why companies write a company brochure - what their 'hidden' intentions behind a brochure could be apart from the 'official' one of promoting the company. So inspired by the basis tenets of systemic functional linguistics (namely that the cultural and situational context adds meaning and purpose to a text), I suggest in my thesis that if we want to find out what the purpose of a text is, we have to consult the context in which the text is used.

Thus in order to move beyond the obvious purpose of "promoting something' and to deduct what the company is trying to achieve through its promotion, we have to turn to the industrial market and the goals and intentions of the participants in the industrial market.

And only by studying the participants - both the sender and the receiver of the company brochures - we can begin to get an idea of the purpose of a company brochure. Furthermore, we may realise that there may be more than one purpose to a company brochure and that the purposes which we deduct depend on the values and attitudes of those doing business in the industrial market.

The two company brochures studied in my thesis are from a dairy ingredient manufacturer and a packaging manufacturer. Both texts are primarily used as promotional material in the industrial market. My analysis of the cultural context of the industrial market is based on a Swedish theory of sociology - the so-called Network approach. The Network approach suggests that the establishment of long-lasting trading relationships is paramount in today's industrial market - thus being able to cooperate is an essential tool and a highly valued asset. It follows from this that one of the main marketing objectives is to present the company as a qualified partner. Here the company brochure plays an important role. Even though the brochures cannot establish partnerships in themselves, they can facilitate the establishment by presenting the company as a qualified partner. It should also be added here that my linguistic studies of the brochures reflected such a purpose; namely the purpose of presenting the company as a qualified partner. I.e. the choice of words and grammatical structures made in the text emphasised the qualities of a great and reliable business partner. 
Thus we see that by studying the context of a text and not least the participants in this context we end up being able to say something about the wide range of hidden purposes which people also intend to realise by means of a text (whether in fact the receiver 'gets the message' is a completely different story which I shall not go into here). Such 'hidden' purposes may for example be:

- to mould public opinion

- to create an image of a reliable business partner

- to obtain financial support

- etc.

What those hidden' purposes have in common is that:

- they cannot be assigned to one particular genre (we can try to form partnerships by means of a wide range of genres such as annual reports, letters, advertisements, etc.)

- they are extremely subjective (my purpose of writing a research article may by different from yours)

- $\quad$ and they are indefinite; there may be fifty reasons for publishing a company brochure for example.

The last point leads me to address the question of the multifunctionality of texts (which also illustrates the difficulty in connection with using communicative purpose as genre determinant). Texts seldom fulfil one function only. Swales' analyses of research articles (Swales 1990) and my analyses of company brochures (Askehave 1998) are good examples of that. I would certainly refrain from assigning one purpose to a text. The reason is that, as mentioned above, the purpose of a text is subjective. My reason for producing a text may be very different from yours- it depends on the person writing the text and the context in which he finds himself.

\section{Conclusion}

As the reader may have realised by now I am not particularly happy with the concept of 'communicative purpose' as genre determinant. I find Swales' use of the term problematic because if we say, as we saw in the case of Bhatia's work that the purpose of a genre is 'to promote something' and thus uses the term 'promotional genre' as a generic 
category, we end up defining company brochures, job applications, tourist promotion, magazine advertisements and book blurbs (and why not research articles?) as instances of the same genre - the promotional genre - and consequently are stuck with extremely broad genre categories. At the same time the notion of communicative purpose is problematic because if we accept that genres serve different purposes, according to which purpose should we categorise the text - is one purpose more primary than the other? And which of the purposes can be said to have a linguistic reflex - in terms of realising a specific schematic structure?

Martin's concept of communicative purpose is not particularly useful either. Martin acknowledges that people may have personal reasons for producing a text. However, he finds this area of speaker intention impossible to deal with and the result is that he only accounts for communicative purposes which are more or less what some of us associate with the purpose of text types. It also means that his framework is not appropriate for handling a complete genre (like for example a company brochure). Martin would split up the genre into descriptive, expository and narrative text types and deal with the purpose of those text types only (which is to describe, explain and narrate) and not the purpose of the entire brochure as such.

This paper is only meant to illustrate the problems we face if we use communicative purpose as the primary means of classifying texts. As suggested in the previous sections the concept is difficult to use for classifying texts because the purpose of a text is far from the reliable measuring device which genre theories seem to suggest. This does not mean, however, that I suggest the phenomenon should be left alone and should not be dealt with at all. As a matter of fact I find it to be one of the most interesting aspects of text analysis - namely that of trying to find out what the intention behind a particular text is.

Well, what about our fundamental urge to classify things then?

I cannot suggest the one and only method for classifying texts. As mentioned at the beginning of this article parameters of 'language', 'situation' and 'function' are all important aspects of language use and should all be dealt with when doing text analysis. And perhaps we ought to attach equal importance to all three parameters when clasifying texts instead of placing primary emphasis one of them. Or maybe we should accept that language use is simply one of those things that 
cannot be pigeonholed and therefore be satisfied with making thorough analyses of separate instances of language use.

\section{References}

Askehave, I. (in press). 'How Do We Account for the Purpose of Texts? - A Critical View on Genre Theory'.

Askehave, I. (1998). A Functional Interpretation of Company Brochures - from context to text. Ph.D.-thesis. The Aarhus School of Business.

Bhatia, V.K. (1993). Analysing Genre: language use in professional settings. Longman Biber, D.(1988). Variation across Speech and Writing. Cambridge University Press.

Eggins, S. (1994). An Introduction to Systemic Functional Linguistic. Pinter.

Eggins, S. \& Martin, J.R. (1997). Genres and Registers of Discourse. In van Dijk, T.A. (ed). Discourse as Structure and Process - Discourse Studies: a multidisciplinary introduction, Vol. I. Sage Publications.

Halliday, M.A.K. (1978). Language as Social Semiotic. Edvard Arnold.

Halliday, M.A.K \& Hasan, R. (1976). Cohesion in English. Longman.

Halliday; M.A.K, McIntosh, A. \& Strevens, P. (1964). The Linguistic Sciences and Language Teaching. The English Language Book Society and Longman Group Ltd.

Henderson, W. \& Hewings, A. (1987). A link between genre and schemata: a case study of economics text'.In ELR Journal 1.

Martin, J.R. (1984). Language, Register and Genre. In Christie, F. (ed). Children Writing: reader. Deakin University Press.

Martin, J.R. (1985a). Process and Text: two aspects of semiosis. In Benson, J.D. \& Greaves, W.S. (eds). Systemic Perspectives on Discourse. Vol. I: Selected theoretical papers form the $9^{\text {th }}$ International Systemic Workshop. Ablex.

Martin, J.R. (1985b). Factual Writing: exploring and challenging social reality. Deakin University Press.

Martin, J.R. (1992). English Text: System and Structure. Benjamins.

Miller, C.R. (1984). Genre as social action. In Quarterly Journal of Speech 70.

Paltridge, B. (1994). Genre Analysis and the Identification of Textual Boundaries. InApplied Linguistics. Vol. 15. Oxford University Press.

Swales, J.M. (1990). Genre Analysis - English in academic and research settings. Cambridge University Press.

Salager-Meyer, F. (1994). Hedges and textual communicative function in medical written English discourse. In English for Specific Purposes 13(2).

Tarone, E., Dwyer, S., Gillette, S. \& Icke, V. (1981). On the use of the passive in two astrophysics journal papers. In The ESP Journal 1(2).

Werlich, E. (1976). A Text Grammar of English. Quelle \& Meyer. 
